\title{
PROGRESS IN ELECTRICAL AND OPTICAL PROPERTIES OF VANADIUM IONS DOPED (PVA+ZnO) POLYMER FILMS
}

\author{
Ch. Rani ${ }^{1, *}$, M. Hemalatha ${ }^{2}$, S. Hima Bindu ${ }^{3}$ and Ch. Linga Raju ${ }^{4}$ \\ ${ }^{1}$ Department of Science and Humanities, Faculty of physic, Guntur Engineering College, Guntur. \\ ${ }^{2}$ Department of Physics, Acharya Nagarjuna University, Nagarjuna Nagar, Guntur. \\ ${ }^{3}$ Department of Physics, National Institute of Technology, Warangal. \\ ${ }^{4}$ Department of Physics, Associate professor, Acharya Nagarjuna University, Nagarjuna Nagar, Guntur. \\ *E-mail: chatla.rani84@gmail.com
}

\begin{abstract}
The various concentrations of vanadium ions doped in $(\mathrm{PVA}+\mathrm{ZnO})$ polymer films prepared by the slow evaporation method and the electrical, optical, and structural properties of polymer films investigated by EPR, optical, and FTIR spectroscopy. The EPR spectrum exhibits lande g- factor $\mathrm{g}_{\|}=1.96, \mathrm{~g}_{\perp}=2.04$, and the hyperfine splitting constant values were $A_{\|} \geq A \perp$. The optical absorption spectrum shows three bands at $420 \mathrm{~nm}, 692 \mathrm{~nm}$, and $832 \mathrm{~nm}$. The bandgap energy of polymer films decreased with increases in vanadium ions concentration. This change indicates that polymer films became more semiconducting. The $(\mathrm{PVA}+\mathrm{ZnO})$ polymer films show an evident change by the addition of vanadium ions and the structural peaks at 1003,1079, 1142, 1271 $\mathrm{cm}^{-1}$ from the FTIR spectrum.

Keywords: Magnetic Stirrer, Distilled Water, Polyvinyl Alcohol, Zinc Oxide, Vanadium Sulphate.
\end{abstract}

(C) RASĀYAN. All rights reserved

\section{INTRODUCTION}

Polymer-salt film compositions of vanadium and water-soluble polymers like PVA are the base for promising hybrid polyfunctional materials. Their properties are controlled to a great extent by complex formation between polymer and salt components. These films exhibit unique features, which are not intrinsic to either of the components. Electrophysical properties of PVA-Vanadium compositions are essential for both scientists and engineers ${ }^{1}$. Organic polymers doped with transition metals oxides like $\mathrm{V}_{2} \mathrm{O}_{5}$ exhibits metallic and semiconductor conduction has attracted ever closer attention of researchers. The effect of $\mathrm{V}_{2} \mathrm{O}_{5}$ on polymeric materials proved by some experiments; these materials powerfully lean on the successes of improving their electrical and optical properties ${ }^{2}$.

Scientists are continuously searching for effective new materials for optoelectronics, microelectronics, and molecular electronics all over the world. In the present work, we used polyvinyl alcohol (PVA) $\left(-\mathrm{CH}_{2}-\mathrm{CH}-\mathrm{OH}-\right)$ n, which consists of hydroxyl groups bound to methane carbons with a carbon chain backbone. The formation of polymer films is due to the $\mathrm{OH}$ groups, which can be a source of hydrogen bonding. PVA used as a binder and electrochemical window due to its high tensile strength and excellent absorption resistance ${ }^{3-5}$. Zinc oxide is one of the most effective materials for the manufacture of future generation optoelectronic devices in the Ultra-Violet region and optical display devices. It has a high exciton binding energy $(60 \mathrm{meV})$, much higher than that of $\mathrm{Ge}(25 \mathrm{meV})$ at room temperature. Zinc oxide shows much more resistant to radiation damage ${ }^{5}$. Vanadyl ion $\left(\mathrm{VO}^{2+}\right)$ is the most steady cation among a few molecular paramagnetic transition metal ions, which is used as an impurity probe extensively for EPR studies. Vanadium doped zinc polymer films attracted researchers because of improved electric, magnetic, optical, and semiconducting properties. Vanadium doped in zinc can abruptly increase its piezoelectric charge coefficient value and vary promising for the fabrication of high performance in nanogenerators ${ }^{6}$.

The present work focused on spectroscopic investigations of vanadyl doped (PVA+ZnO) polymer complexes. The effect of vanadyl ion on the $(\mathrm{PVA}+\mathrm{ZnO})$ complex is the main aim of the present study. The polymer films verified and studied with the EPR, optical absorption, and FTIR studies.

Rasayan J. Chem., 13(2), 887-897(2020)

http://dx.doi.org/10.31788/RJC.2020.1325582 
RASĀYAN J. Chem.

Vol. 13 | No. 2 |887 - 897| April - June | 2020

\section{EXPERIMENTAL}

The high-quality chemicals Polyvinyl (alcohol) (PVA), zinc acetate $\left.\left(\mathrm{CH}_{3} \mathrm{COO}\right)_{2} \mathrm{Zn} \cdot 2 \mathrm{H}_{2} \mathrm{O}\right)$, Vanadium sulphate $\left(\mathrm{V}_{2} \mathrm{O}_{5} . \mathrm{SO}_{4}\right)$, and the double-distilled water used for the preparation of reactant solutions and collected by National scientific products Pvt. Ltd., Guntur, India.

$5 \mathrm{~mol} \%$ of each PVA and zinc acetate solutions were prepared separately by dissolving commercial AR grade chemicals using double distilled water as a solvent with gently heating in water both. The two solutions stirred until the polymer wholly dissolved and forms a uniform, transparent, viscous solution. Then the two solutions were mixed and stirred for $30 \mathrm{~min}$ using a magnetic stirrer. The desired concentration of $\mathrm{V}_{2} \mathrm{O}_{5} \cdot \mathrm{SO}_{4}$ solutions were mixed with $5 \mathrm{~mol} \%$ of $(\mathrm{PVA}+\mathrm{ZnO})$ solutions and stirred thoroughly with a magnetic stirrer. The final solution poured into the Petri dishes. The films were grown by slow evaporation in dry air and peeled off from the Petri dishes after seven days. The prepared films are light greenish color with a thickness of approximately $1 \mathrm{~mm}$. Hereafter the $(\mathrm{PVA}+\mathrm{ZnO})$ referred to as PVAZn films. The photographs of prepared samples shown in Fig.-1.
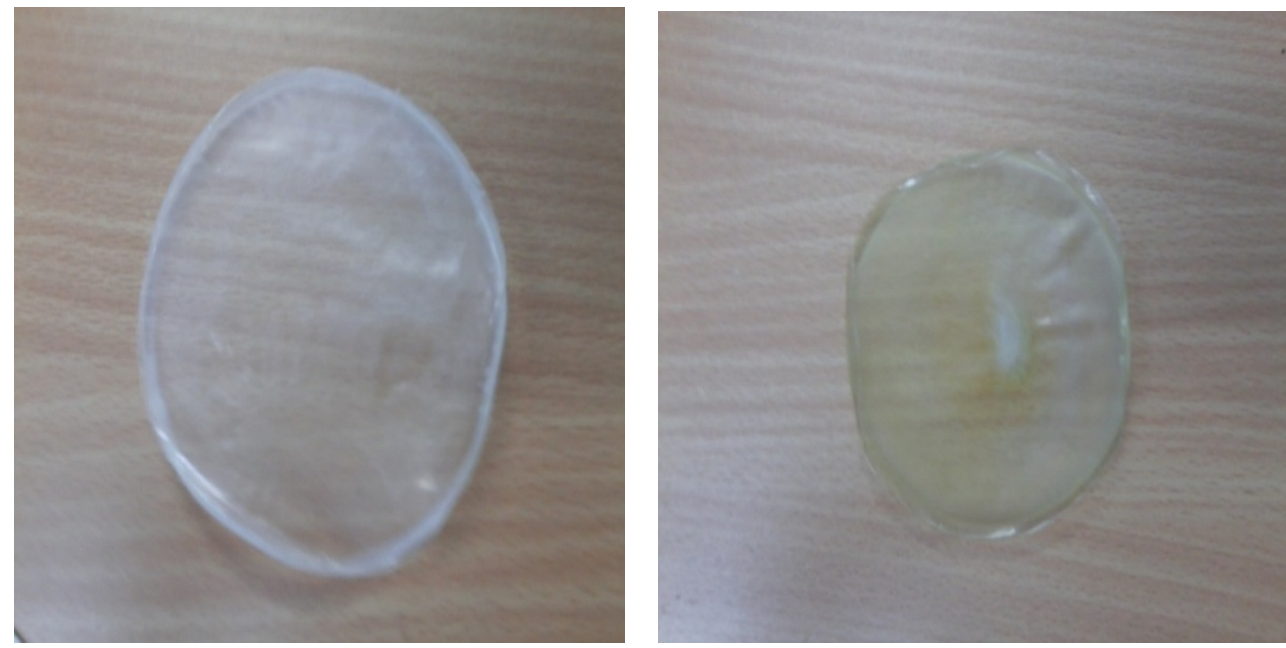

Fig.-1: A Photograph of Pure PVAZn and PVAZn: $\mathrm{VO}_{2}+(0.8$ mol\%) Polymer Films.

\section{EPR Studies}

\section{RESULTS AND DISCUSSION}

Vanadyl ion has the electronic configuration $[\mathrm{Ar}] 3 \mathrm{~d}^{1}$, which thereby leads to paramagnetism in $\mathrm{VO}^{2+}$. The ${ }^{51} \mathrm{~V}$ nucleus $(99.8 \%$ ) abundant has a nuclear spin $\mathrm{I}=7 / 2$ and a massive magnetic moment. No Electron Paramagnetic Resonance signal observed in the spectra of undoped PVAZn polymer film, indicating that no paramagnetic signatures(EPR) were present in the starting materials. When various mol\% of vanadyl ions added to the PVAZn complex, the EPR spectra of all the investigated samples exhibit well-resolved resonance signals. The Electron Paramagnetic Resonance Spectra of vanadyl ions doped PVAZn polymer films shown in Fig.-2. There is no specific effect of $\mathrm{VO}^{2+}$ ion concentration on the structure of the PVAZn: $\mathrm{VO}^{2+}$ polymer film except the variation in intensity.

Generally, an eight component hyperfine structure expected from the ${ }^{51} \mathrm{~V}$ nucleus and the electronic moment of the paramagnetic $\mathrm{V}^{4+}$ ions. Due to the dipole-dipole interaction between them. An axial spinHamiltonian, which includes the hyperfine interaction, has been used to describe the EPR spectra of $\mathrm{V}^{4+}$. The EPR spectra analyzed using the spin-Hamiltonian equation of the form ${ }^{7}$,

$$
\mathrm{H}=\mathrm{g}_{\|} \beta \mathrm{H}_{\mathrm{z}} \mathrm{S}_{\mathrm{z}}+\mathrm{g}_{\perp}\left(\mathrm{H}_{\mathrm{x}} \mathrm{S}_{\mathrm{x}}+\mathrm{H}_{\mathrm{y}} \mathrm{S}_{\mathrm{y}}\right)+\mathrm{A}_{\|} \mathrm{I}_{\mathrm{z}} \mathrm{S}_{\mathrm{z}}+\mathrm{A}_{\perp}\left(\mathrm{I}_{\mathrm{x}} \mathrm{S}_{\mathrm{x}}+\mathrm{I}_{\mathrm{y}} \mathrm{S}_{\mathrm{y}}\right)
$$

Where, $\beta$ is the Bohr magneton. $\mathrm{H}_{\mathrm{x}}, \mathrm{H}_{\mathrm{y}}, \mathrm{H}_{\mathrm{z}}$ are the static magnetic field components. $\mathrm{S}_{\mathrm{x}}, \mathrm{S}_{\mathrm{y}}$, and $\mathrm{S}_{\mathrm{z}}$ are the spin operators of the electron. $I_{x}, I_{y}$, and $I_{z}$ are the spin operators of the nucleus. $g_{\|}$and $g_{\perp}$ are the parallel and perpendicular values of the anisotropic $g$ tensor. Here $\mathrm{A}_{\|}$and $\mathrm{A}_{\perp}$ are parallel and perpendicular hyperfine values of the hyperfine tensor ' $A$ ' and nuclear quadrupole contribution is neglected. 
RASĀYAN J. Chem.

Vol. 13 | No. 2 |887 - 897| April - June | 2020

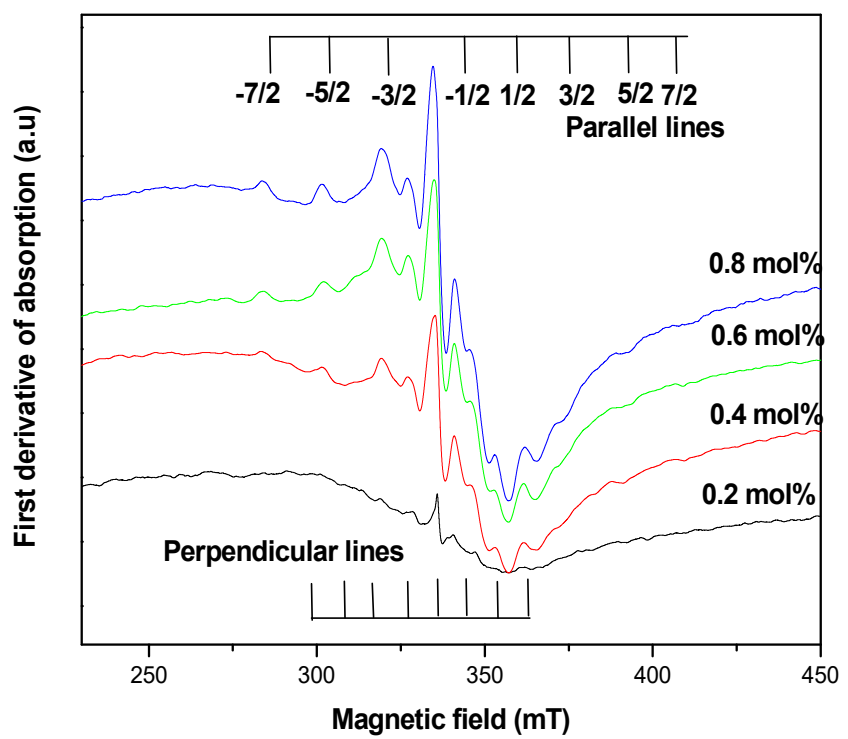

Fig.-2: EPR Spectra of PVAZn: $\mathrm{VO}^{2+}(0.2-0.8 \mathrm{~mol} \%)$ Films at Room Temperature.

In order to describe the ${ }^{51} \mathrm{~V}$ in our EPR experiments, the magnetic field positions of the hf's lines expressed as,

$$
\begin{aligned}
& \mathrm{H}_{\|}\left(\mathrm{m}_{\mathrm{I}}\right)=\left(\mathrm{h} v / \mathrm{g}_{\|} \mu \mathrm{B}\right)-\mathrm{m}_{\mathrm{I}} \mathrm{A}_{\|}-\left(63 / 4-\mathrm{m}_{\mathrm{I}}^{2}\right) \mathrm{A}_{\perp}^{2}\left(\mathrm{~g}_{\|} \mu_{\mathrm{B}} / \mathrm{h} v\right) \\
& \mathrm{H}_{\perp}\left(\mathrm{m}_{\mathrm{I}}\right)=\left(\mathrm{h} v / \mathrm{g}_{\perp} \mu \mathrm{B}\right)-\mathrm{m}_{\mathrm{I}} \mathrm{A}_{\perp}-\left(63 / 4-\mathrm{m}_{\mathrm{I}}^{2}\right)\left(\mathrm{A}_{\|}^{2}+\mathrm{A}_{\perp}^{2}\right)\left(\mathrm{g}_{\perp} \mu_{\mathrm{B}} / \mathrm{h} v\right)
\end{aligned}
$$

Where $\mathrm{h}$ is the Plank's constant, $v$ the microwave frequency, ' $\mathrm{m}_{\mathrm{I}}$ ' is the magnetic quantum number of the vanadium nucleus, which takes the values $\pm 7 / 2, \pm 5 / 2, \pm 3 / 2$ and $\pm 1 / 2$. The spin-Hamiltonian parameters are calculated using Eqs. -2 and 3.

The two fundamental parameters derived from EPR spectral measurements, Lande g- factor and the electron-nuclear spin coupling constant (A) for the $\mathrm{VO}^{2+}$ ion-doped PVAZn polymer film, are evaluated and are given in Table-1. For $\mathrm{VO}^{2+}$ ions, the increase in values of $\mathrm{g}_{\|}$and $\mathrm{g}_{\perp}$ depend on the vanadiumligand distance, which is due to the shortening of $\mathrm{V}-\mathrm{O}$ and $\mathrm{V}=\mathrm{O}$ bond lengths. The experimentally obtained $g$ values are more or less constant at $g_{\|}=1.96$ and $\mathrm{g}_{\perp}=2.04$ for all the concentrations of vanadium ions and $\mathrm{A}_{\|}>\mathrm{A}_{\perp}$. The $\mathrm{g}$ and $\mathrm{A}$ values obtained in the present work are close to those vanadyl complexes reported in the literature ${ }^{8-10}$. Here the vanadyl ions in PVAZn polymers exist as $\mathrm{VO}^{2+}$ ions. The vanadium ions octahedral coordination with a tetragonal compression and has $\mathrm{C}_{4 \mathrm{v}}$ symmetry.

The term $\Delta \mathrm{g}_{\|} / \Delta \mathrm{g}_{\perp}$ indicates the extent of tetragonal distortion, which relates to the bond strength of both $\mathrm{V}$ double bond oxygen $(\mathrm{V}=\mathrm{O})$ and $\mathrm{V}$ single bond oxygen $(\mathrm{V}-\mathrm{O})$ ligand. The values of $\Delta \mathrm{g}_{\|} / \Delta \mathrm{g}_{\perp}$ (where $\Delta \mathrm{g}_{\|}=\left(2.0023-\mathrm{g}_{\|}\right)$and $\left.\Delta \mathrm{g}_{\perp}=\left(2.0023-\mathrm{g}_{\perp}\right)\right)$ is also calculated and are presented in Table 1. It observed that $\Delta \mathrm{g}_{\|} / \Delta \mathrm{g}_{\perp}$ value decreases with vanadyl content up to $0.6 \mathrm{~mol} \%$. This decrease indicates that the symmetry around $\mathrm{VO}^{2+}$ ions is improved. The vanadyl ions are in tetragonally less distorted octahedral sites. On the further increase of vanadyl content, the $\Delta \mathrm{g}_{\|} / \Delta \mathrm{g}_{\perp}$ increases. This change implies that as the concentration increases, the deviation from octahedral symmetry increases. So that the $\mathrm{VO}^{2+}$ ions are more tetragonally distorted ${ }^{11}$.

In the absence of covalency, the parallel and perpendicular components of the hyperfine tensor can be written as ${ }^{12}$

$$
\begin{aligned}
& \mathrm{A}_{\|}=-\mathrm{P}\left[(4 / 7)+\left(\mathrm{g}_{\|}-2.0023\right)+(3 / 7)\left(\mathrm{g}_{\perp}-2.0023\right)+\mathrm{k}\right] \\
& \mathrm{A}_{\perp}=\mathrm{P}\left[(2 / 7)+(11 / 14)\left(\mathrm{g}_{\perp}-2.0023\right)-\mathrm{k}\right]
\end{aligned}
$$

Where, ' $\mathrm{P}$ ' is the dipolar hyperfine coupling constant given by $\mathrm{P}=2 \gamma \beta \beta \mathrm{N}<\mathrm{r}^{-3} \geq 0.0128 \mathrm{~cm}^{-1}$, where $\mathrm{r}^{3}$ is the average size of the vanadium $3 \mathrm{~d}$ orbital. It accounts for the dipole-dipole interaction of electron 
RASĀYAN J. Chem.

Vol. 13 | No. 2 |887 - 897| April - June | 2020

moment with the nuclear moment. ' $\mathrm{k}$ ' is the dimensionless Fermi contact interaction parameter, which constitute the quantity of unpaired electron density at the vanadium nucleus. In other words, it accounts for the contribution of an admixture of s-electrons to the value of hyperfine structure constant.

Bleaney and Stevens ${ }^{13}$ reported, the quantity $\mathrm{Pk} / \gamma_{\mathrm{g}}\left(\gamma_{\mathrm{g}}\right.$ is the gyromagnetic ratio) is constant for iron group ions, and it takes the values $0.006,0.0054,0.0067$ and $0.006 \mathrm{~cm}^{-1}$ for $\mathrm{Cu}^{2+}, \mathrm{Cr}^{3+}, \mathrm{Mn}^{2+}$, and $\mathrm{VO}^{2+}$ ions respectively. To get this value, authors should take negative values for $\mathrm{A}_{\|}$and $\mathrm{A}_{\perp}$ and evaluated ' $\mathrm{P}$ ' and ' $\mathrm{k}$ ' values for the samples presented in Table-1. For the ${ }^{51} \mathrm{~V}$ nucleus, the value of the gyromagnetic ratio $\gamma_{\mathrm{g}}$ is 1.468. ${ }^{10}$ By using this value, the authors evaluated $\mathrm{Pk} / \gamma_{\mathrm{g}}$ and obtained the value as 0.008 , which is approximately equal to those vanadyl complexes reported in the literature ${ }^{14,15}$. The parameter ' $\mathrm{k}$ ' indicates extreme sensitivity to the distortion of the electron orbits of the central vanadium ion. The high values of ' $\mathrm{k}$ ' indicate a significant contribution to the hyperfine constant by the unpaired 's' electron.

\section{Spin Concentration}

The concentration of $\mathrm{V}^{4+}$ centers was determined by double numerical integration of the EPR spectrum of $\mathrm{V}^{4+}$ signal and comparing with the reference sample. Here the copper is taken as a reference sample for the calculations. The formula is given by ${ }^{16}$,

$$
\mathrm{N}=\left[\mathrm{A}_{\mathrm{x}}\left(\mathrm{P}_{\mathrm{Std}}\right)^{1 / 2}\left(\mathrm{Scan}_{\mathrm{x}}\right)^{2} \mathrm{G}_{\mathrm{std}}\left(\mathrm{B}_{\mathrm{m}}\right)_{\text {std }}\left(\mathrm{g}_{\mathrm{std}}\right)^{2}[\mathrm{~S}(\mathrm{~S}+1)]_{\mathrm{std}}\right] / \mathrm{A}_{\text {std }}\left(\mathrm{P}_{\mathrm{x}}\right)^{1 / 2}\left(\mathrm{scan}_{\mathrm{std}}\right)^{2} \mathrm{G}_{\mathrm{x}}\left(\mathrm{B}_{\mathrm{m}}\right)_{\mathrm{x}}\left(\mathrm{g}_{\mathrm{x}}\right)^{2}[\mathrm{~S}(\mathrm{~S}+1)]_{\mathrm{x}}[\mathrm{Std}]
$$

Where, $\mathrm{N}$ is the number of spins participating in resonance, and $\mathrm{A}$ is the area under the absorption curve. 'Scan' is the magnetic field corresponding to the unit length of the chart, $G$ is the gain, $B_{m}$ is the modulation field width, $\mathrm{g}$ is the $\mathrm{g}$ - factor, $\mathrm{S}$ is the spin of the system in its ground state, $\mathrm{P}$ is the power of the microwaves. The subscripts ' $\mathrm{x}$ ' and 'std' represents the corresponding quantities for the PVAZn: $\mathrm{VO}^{2+}$ polymer films and copper sample ${ }^{17,18}$. A plot drawn between $\log \mathrm{N}$ against different concentrations of $\mathrm{VO}^{2+}$ ions is shown in Fig.-3. From the graph, it observed that the no. of spins increases with $\mathrm{VO}^{2+}$ concentration except at $0.6 \mathrm{~mol} \%$ of vanadium. At $0.6 \mathrm{~mol} \%$ of $\mathrm{VO}^{2+}$ ions, the spin concentration decreases due to the dipolar interactions between the vanadyl ions ${ }^{11}$.

From the EPR spectral information, the magnetic susceptibilities calculated for different concentrations of $\mathrm{VO}^{2+}$ ions using the formula ${ }^{19}$,

$$
\chi=\left[\mathrm{Ng}^{2} \beta^{2} \mathrm{~J}(\mathrm{~J}+1)\right] / 3 \mathrm{~K}_{\mathrm{B}}(\mathrm{T})
$$

Where, ' $\mathrm{N}$ ' is the spin concentration per $\mathrm{kg}$, ' $\mathrm{J}$ ' is the total angular momentum, ' $\beta$ ' is the Bohr magneton, ' $\mathrm{K}_{\mathrm{B}}$ ' is the Boltzmann constant, and ' $\mathrm{T}$ ' is the absolute temperature. The concentrations of spins ' $\mathrm{N}$ ' can be calculated by double integrating the first derivative EPR spectrum by using Eq.-6, $g=\left[\left(g_{\|}+2 g_{\perp}\right) / 3\right]$ taken from EPR data. By using the above equation, the paramagnetic susceptibilities calculated as a function of $\mathrm{VO}^{2+}$ ion concentration. Fig.:-4 shows a plot of $1 / \chi$ as a function of different concentrations of $\mathrm{VO}^{2+}$ ions in PVAZn: $\mathrm{VO}^{2+}$ polymer film.

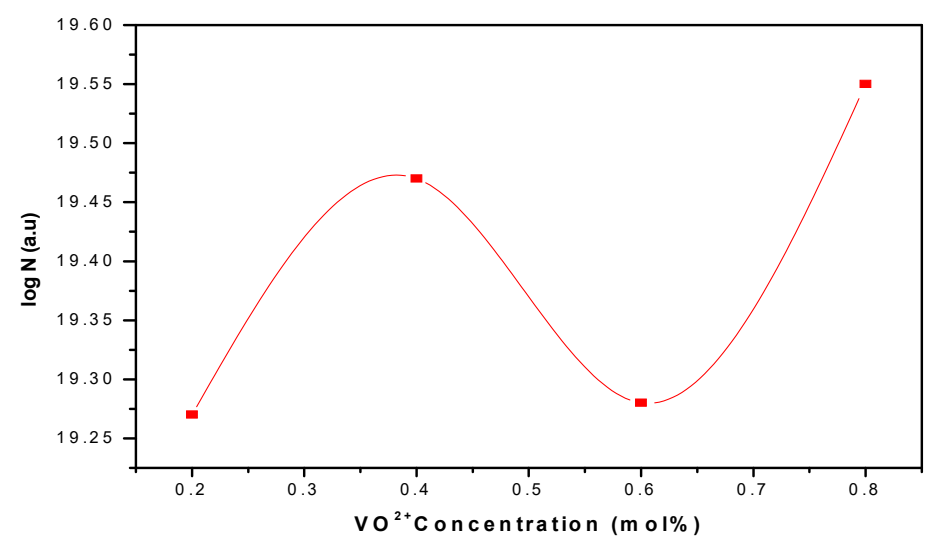

Fig.-3: A Plot of $\log \mathrm{N}$ against $\mathrm{VO}^{2+}$ Ion Concentrations in PVAZn Films at Room Temperature. 
RASĀYAN J. Chem.

Vol. 13 | No. 2 |887 - 897| April - June | 2020

Table-1: The Spin-Hamiltonian Parameters, Molecular Orbital Bonding Coefficients for PVAZn: VO $^{2+}$ Polymer Films.

\begin{tabular}{l|c|c|l|l|l|l|l|l|l|l|l}
\hline $\begin{array}{c}\mathrm{VO} 2+ \\
(\mathrm{mol} \%)\end{array}$ & $\mathrm{g}_{\|}$ & $\mathrm{g}_{\perp}$ & $\begin{array}{c}\mathrm{A}_{\|} \mathrm{x} 10-4 \\
\left(\mathrm{~cm}^{-1}\right)\end{array}$ & $\begin{array}{c}\mathrm{A}_{\perp} \mathrm{x} 10^{-4} \\
\left(\mathrm{~cm}^{-1}\right)\end{array}$ & $\begin{array}{c}\Delta \mathrm{g}_{\|} \\
/ \Delta \mathrm{g}_{\perp}\end{array}$ & $\begin{array}{c}\mathrm{A}_{\|}^{1} \times 10^{-4} \\
\left(\mathrm{~cm}^{-1}\right)\end{array}$ & $\begin{array}{c}\mathrm{A}_{\perp}^{1} \times 10^{-4} \\
\left(\mathrm{~cm}^{-1}\right)\end{array}$ & $\begin{array}{c}\mathrm{P} \mathrm{x} 10^{-4} \\
\left(\mathrm{~cm}^{-1}\right)\end{array}$ & $\mathrm{K}$ & $\alpha^{2}$ & $\beta^{2^{*}}$ \\
\hline 0.2 & 1.96 & 2.04 & 177 & 100 & 1.12 & 55 & 28 & 93 & 1.39 & 1.042 & 1.02 \\
\hline 0.4 & 1.96 & 2.04 & 173 & 111 & 1.09 & 42 & 23 & 71 & 1.87 & 1.085 & 1.06 \\
\hline 0.6 & 1.96 & 2.06 & 175 & 102 & 1.02 & 50 & 28 & 86 & 1.51 & 1.056 & 1.02 \\
\hline 0.8 & 1.95 & 2.04 & 179 & 102 & 1.39 & 43 & 22 & 70 & 1.76 & 1.390 & 1.16 \\
\hline
\end{tabular}

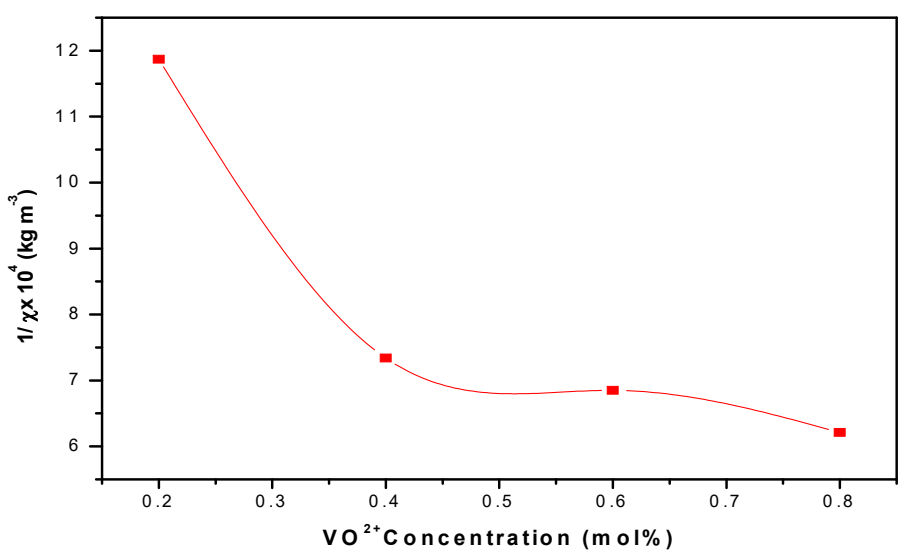

Fig.-4: A Plot is drawn between the Reciprocal of Susceptibility against Different Concentrations of Vanadyl Ions in

\section{Optical Absorption Studies}

$$
\text { PVAZn: } \mathrm{VO}^{2+} \text { Polymer Films at Room Temperature. }
$$

The optical absorption spectra of different concentrations (0.2-0.8 mol \%) of vanadyl ions doped in PVAZn polymer films shown in Fig.-5(a)

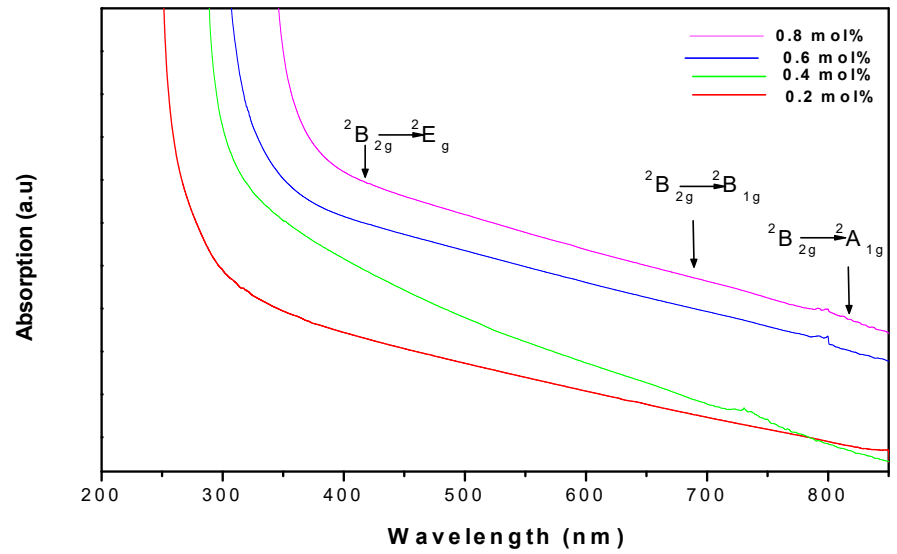

Fig.-5(a): Optical Absorption Spectrum of PVAZn: $\mathrm{VO}^{2+}(0.2-0.8 \mathrm{~mol} \%)$ Polymer Films.

The absorption spectra consist of three bands, centered at $420 \mathrm{~nm}, 692 \mathrm{~nm}$, and $832 \mathrm{~nm}$ and are assigned to ${ }^{2} \mathrm{~B}_{2 \mathrm{~g}} \rightarrow{ }^{2} \mathrm{E}_{\mathrm{g}},{ }^{2} \mathrm{~B}_{2 \mathrm{~g}} \rightarrow{ }^{2} \mathrm{~B}_{1 \mathrm{~g}}$ and ${ }^{2} \mathrm{~B}_{2 \mathrm{~g}} \rightarrow{ }^{2} \mathrm{~A}_{1 \mathrm{~g}}$ transitions, respectively shown in Fig.-5(b, c \& d $)^{20}$. VO $\mathrm{VO}^{2+}$ ion belongs to $\mathrm{d}^{\mathrm{l}}$ configuration and will have a ground state of ${ }^{2} \mathrm{D}$. In octahedral symmetry, the $\mathrm{d}$ electron occupies the $t_{2 g}$ orbital and gives rise to a ${ }^{2} T_{2 g}$ ground state. On excitation, the electron occupies Eg orbital and gives rise to ${ }^{2} \mathrm{E}_{\mathrm{g}}$ state. Thus only one single transition ${ }^{2} \mathrm{~T}_{2 \mathrm{~g}} \rightarrow{ }^{2} \mathrm{E}_{\mathrm{g}}$, and correspondingly a single band is expected for $\mathrm{VO}^{2+}$ ions in octahedral symmetry. However, due to non-symmetrical alignment of the $\mathrm{V}=\mathrm{O}$ bond along the axis, $\mathrm{VO}^{2+}$ site symmetry lowers to tetragonal or rhombic. In a tetragonal symmetry, the ${ }^{2} \mathrm{~T}_{2 \mathrm{~g}}$ level splits into ${ }^{2} \mathrm{~B}_{1 \mathrm{~g}}$ and ${ }^{2} \mathrm{~A}_{1 \mathrm{~g}}$ levels. Accordingly, the optical absorption spectra of $\mathrm{VO}^{2+}$ ions in 
RASĀYAN J. Chem.

Vol. 13 | No. 2 |887 - 897| April - June | 2020

tetragonal symmetry mostly consist of three bands corresponding to the transitions ${ }^{2} \mathrm{~B}_{2 \mathrm{~g}} \rightarrow{ }^{2} \mathrm{~B}_{1 \mathrm{~g}},{ }^{2} \mathrm{~B}_{2 \mathrm{~g}} \rightarrow{ }^{2} \mathrm{E}_{\mathrm{g}}$, and ${ }^{2} \mathrm{~B}_{2 \mathrm{~g}} \rightarrow{ }^{2} \mathrm{~A}_{1 \mathrm{~g}}{ }^{21}$ In the present study, there is no considerable change in the band positions of the allpolymer films with different concentrations of vanadyl ions.

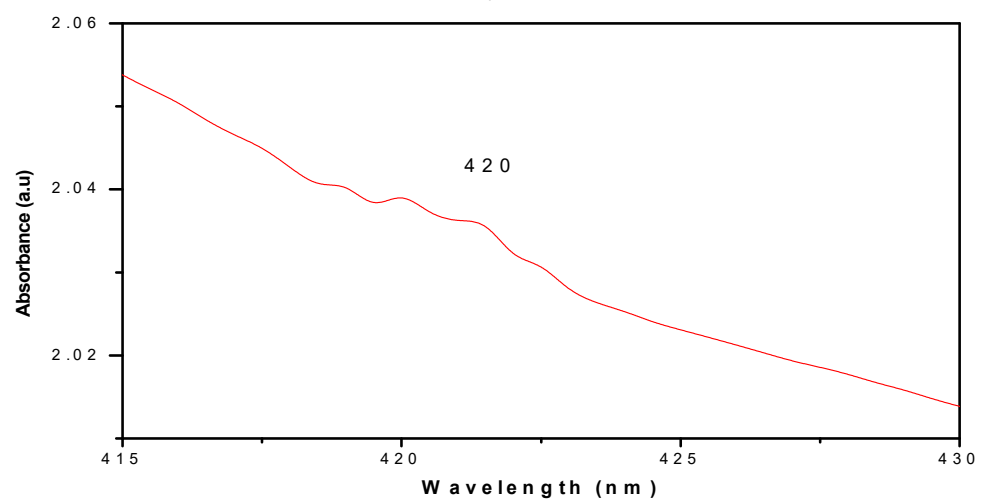

(b)

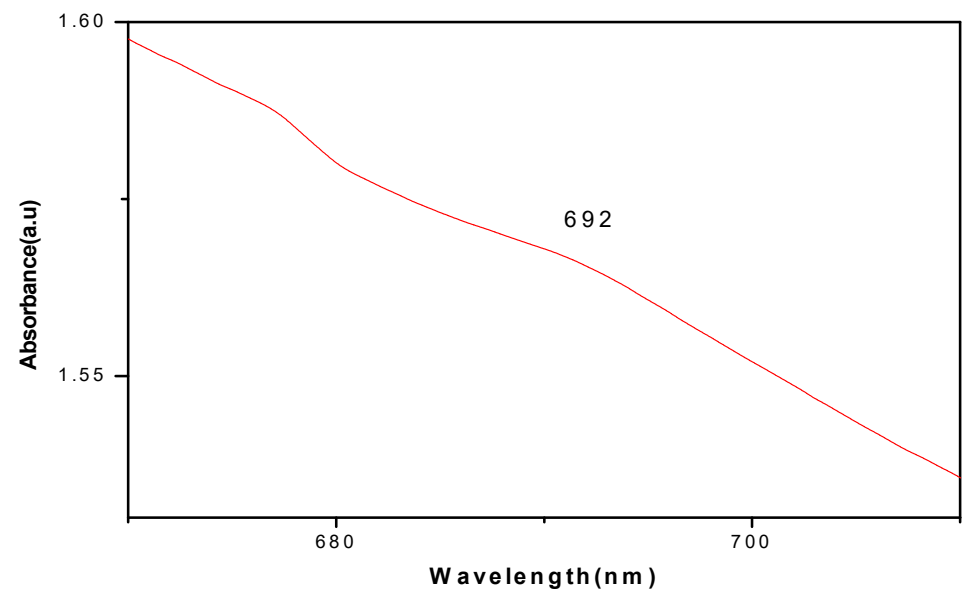

(c)

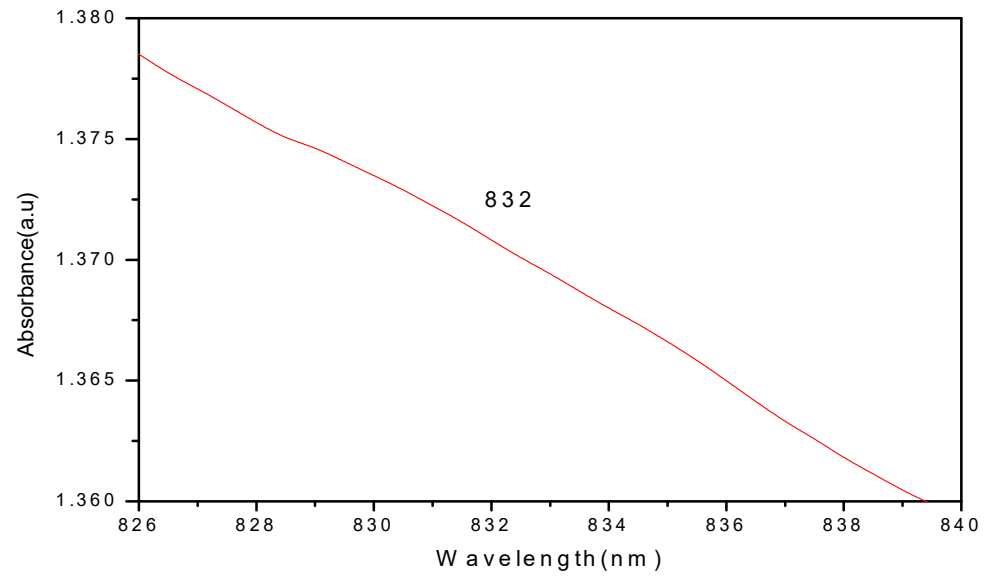

(d)

Fig.-5(b, c and d): The Three Optical Absorption Bands for VAZn: $\mathrm{VO}^{2+}(0.2 \mathrm{~mol} \%)$ Polymer Film.

The absorption bands assigned to the $\mathrm{d}-\mathrm{d}$ transitions corresponding to $\mathrm{VO}^{2+}$ ions. The octahedral and tetragonal crystal field parameters calculated using the expressions,

$$
\begin{aligned}
& { }^{2} \mathrm{~B}_{2 \mathrm{~g}} \rightarrow{ }^{2} \mathrm{E}_{\mathrm{g}}=\mathrm{E}_{1}=-3 \mathrm{D}_{\mathrm{s}}+5 \mathrm{D}_{\mathrm{t}} \\
& { }^{2} \mathrm{~B}_{2 \mathrm{~g}} \rightarrow{ }^{2} \mathrm{~B}_{1 \mathrm{~g}}=\mathrm{E}_{2}=10 \mathrm{D}_{\mathrm{q}}
\end{aligned}
$$


RASĀYAN J. Chem.

Vol. 13 | No. 2 |887 - 897| April - June | 2020

$$
{ }^{2} \mathrm{~B}_{2 \mathrm{~g}} \rightarrow{ }^{2} \mathrm{~A}_{1 \mathrm{~g}}=\mathrm{E}_{3}=10 \mathrm{D}_{\mathrm{q}}-4 \mathrm{D}_{\mathrm{S}}-5 \mathrm{D}_{\mathrm{t}}
$$

The above three equations were solved and the parameters $D_{q}=1445 \mathrm{~cm}^{-1}$, DS $=-3064 \mathrm{~cm}^{-1}$ and $D_{t}=590$ $\mathrm{cm}^{-1}$ are obtained.

The fundamental absorption edge studied in the UV region, which is a useful technique to study the optical transitions and electronic band structure in crystalline and non-crystalline material. The main factor of the absorption edge is an exponential increase in the absorption coefficient ' $\alpha$ ' with photon energy hu. The absorption coefficient ' $\alpha$ ' can be determined as a function of frequency by using the relation,

$$
\alpha(v)=(\mathrm{A} / \mathrm{d}) \times 2.303
$$

Where ' $\mathrm{A}$ ' is the absorbance at frequency ' $\mathrm{v}$ ' and ' $\mathrm{d}$ ' is the width of the sample. The optical band gap for a direct and indirect transition can be calculated using the relation,

$$
\mathrm{E}_{\mathrm{opt}}=\mathrm{hv}-(\alpha \mathrm{h} v / \mathrm{B})^{\mathrm{n}}
$$

The direct bandgap energies $\left(\mathrm{E}_{\mathrm{opt}}\right)$ of the $\mathrm{VO}^{2+}: \mathrm{PVAZn}$ polymers obtained from their ultraviolet absorption by plotting $(\alpha h v)^{2}$ as a function of photon energy hu and shown in Fig.-6.

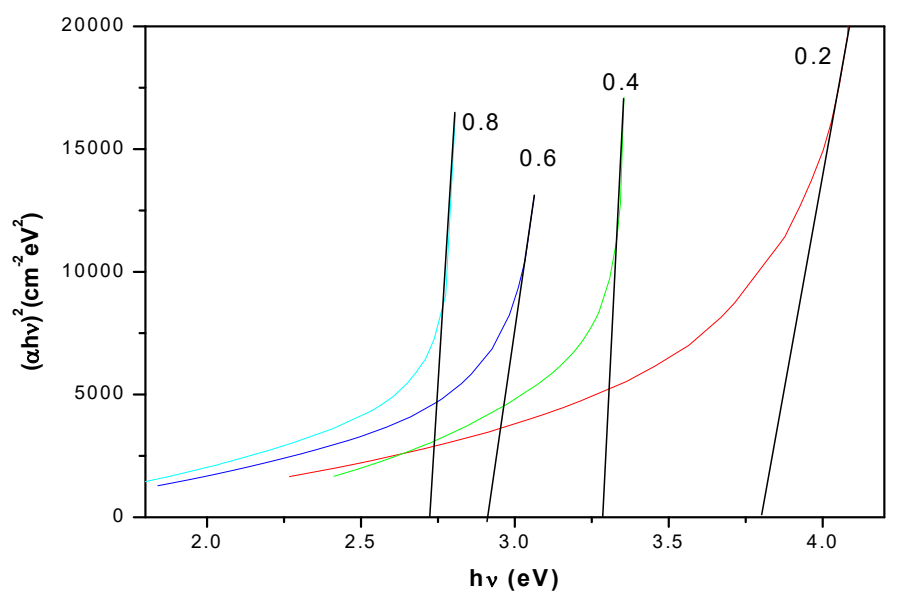

Fig.-6: A Plot between $(\alpha h v)^{2}$ and hv for PVAZn: $\mathrm{VO}^{2+}(0.2-0.8$ mol\%) Polymer Films.

The indirect bandgap energies $\left(\mathrm{E}_{\mathrm{opt}}\right)$ of the PVAZn: $\mathrm{VO}^{2+}$ polymer films calculated from their ultraviolet absorption graphs. The graph by plotting $(\alpha h v)^{1 / 2}$ as a function of photon energy hv. It shows Fig.-7.

The respective values of $\mathrm{E}_{\text {opt }}$ obtained by extrapolating the linear region of the graph towards the $\mathrm{X}$-axis to meet at $(\alpha h v)^{2}=0$ and $(\alpha h v)^{1 / 2}=0$ for direct and direct transitions respectively.

The absorption coefficients in Urbach's tail region given as a function of photon energy by the Eq.-13,

$$
\alpha=\alpha_{0} \exp (\mathrm{h} v / \Delta \mathrm{E})
$$

Here $\alpha_{0}$ is a constant, $\Delta \mathrm{E}$ is the Urbach energy explains the energy gap between localized tails in the forbidden region. Urbach plots are the natural logarithm of the absorption coefficient $\ln (\alpha)$ plotted against photon energy (hu). In the present study, such an Urbach plots for $\mathrm{VO}^{2+}$ : $\mathrm{PVAZn}$ polymer films shown in Fig.-8.

All the direct, indirect optical band gaps and Urbach energy values of PVAZn: $\mathrm{VO}^{2+}$ polymer films calculated. These values tabulated in Table-2.

The direct, indirect and Urbach energies of the PVAZn: $\mathrm{VO}^{2+}$ polymer samples decrease with an increase of vanadyl ion concentration. This increase indicates that with an increase in the strength of $\mathrm{VO}^{2+}$ ions, PVAZn polymer film becomes more semiconducting. 
RASĀYAN J. Chem.

Vol. 13 | No. 2 |887 - 897| April - June | 2020

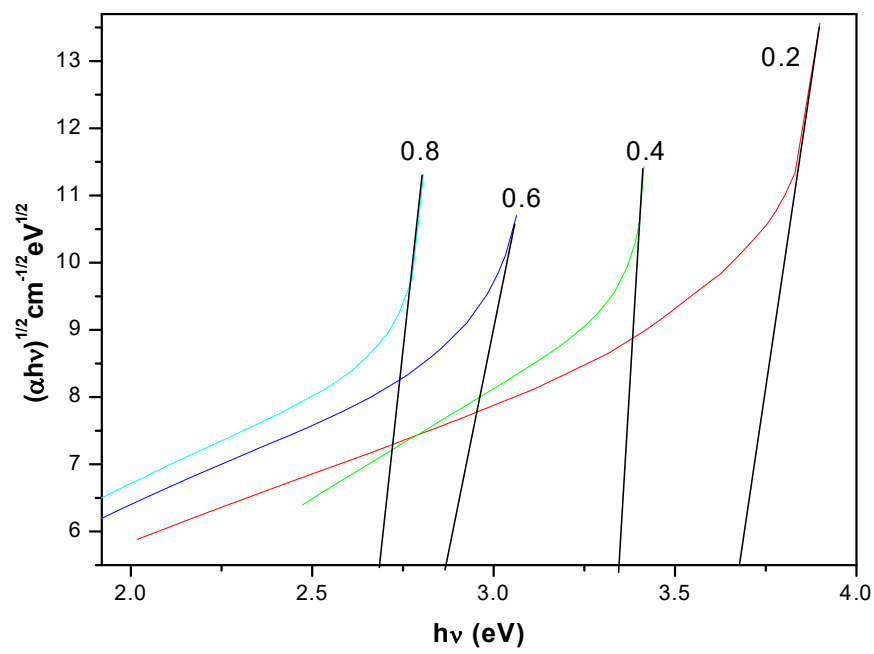

Fig.-7: A Plot Drawn between $(\alpha h v)^{1 / 2}$ and hv for PVAZn: $\mathrm{VO}^{2+}(0.2-0.8 \mathrm{~mol} \%)$ Polymer Films.

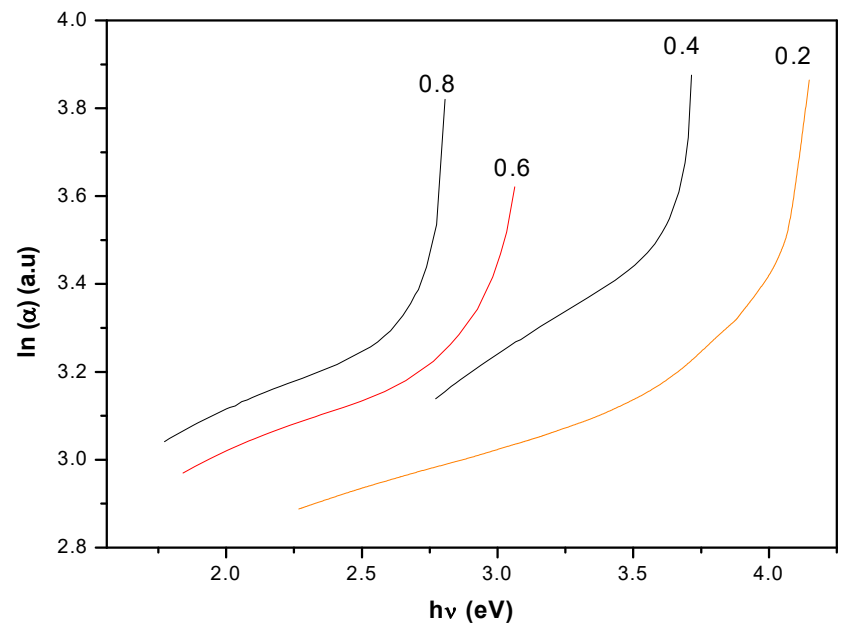

Fig.-8: A Plot between $\ln (\alpha)$ and hv for PVAZn: $\mathrm{VO}^{2+}(0.2-0.8 \mathrm{~mol} \%)$ Polymer Films.

EPR and optical data can be correlated and the molecular orbital theory shows that the components $\mathrm{A}_{\|}$ and $\mathrm{A}_{\perp}$ consists of the contribution from $\mathrm{A}_{\|}{ }^{1}$ and $\mathrm{A}_{\perp}{ }^{1}$ of the $3 \mathrm{~d}_{\mathrm{xy}}$ electron to the hyperfine structure and the $\mathrm{P} \beta_{2}{ }^{* 2} \mathrm{k}$ term arising due to the anomalous contribution of the s-electrons. The modified form of the equations (1.14) \& (1.15) can be written $\operatorname{as}^{22}$,

$$
\begin{aligned}
& \mathrm{A}_{\|}=\mathrm{A}_{\|}{ }^{1}-\mathrm{P} \beta_{2}{ }^{* 2} \mathrm{k} \\
& \mathrm{A}_{\perp}=\mathrm{A}_{\perp}{ }^{1}-\mathrm{P} \beta_{2}{ }^{{ }^{* 2} \mathrm{k}}
\end{aligned}
$$

Where, $\mathrm{A}_{\|}{ }^{1}=\mathrm{P}\left[-\beta_{2}{ }^{* 2}(4 / 7)+\left(\mathrm{g}_{\|}-2.0023\right)+(3 / 7)\left(\mathrm{g}_{\perp}-2.0023\right)+\mathrm{D}_{\|}+(3 / 7) \mathrm{D}_{\perp}\right.$ and $\mathrm{A}_{\perp}{ }^{1}=\mathrm{P}\left[\beta_{2}{ }^{* 2}(2 / 7)+(11 / 4)\left(\mathrm{g}_{\perp}-2.0023\right)+(11 / 4) \mathrm{D}_{\perp}\right]$.

Here $D_{\|}=-0.0125$ and $D_{\perp}=-0.0015$ are small corrections ${ }^{23}$ and other symbols have their usual meanings. Using the EPR data, the molecular orbital coefficients $\alpha^{2}$ and $\beta_{2}{ }^{* 2}$ evaluated, where $\beta_{2}{ }^{* 2}$ is a measure of the degree of $\pi$ bonding with the equatorial ligands. $\alpha^{2}$ represent the in-plane $\sigma$-bonding, which are obtained 
RASĀYAN J. Chem.

Vol. 13 | No. 2 |887 - 897| April - June | 2020

from a suitable linear combination of the $\mathrm{g}_{\|}$and $\mathrm{g}_{\perp}$ and also $\mathrm{A}_{\|}$and $\mathrm{A}_{\perp}$ which are defined by the following equations ${ }^{24,25}$,

$$
\alpha^{2}=(7 / 4)\left[\left(A_{\|}-A\right) / P+(2 / 3) g_{\|}-(5 / 21) g_{\perp}-(6 / 7)\right]
$$

Where ' $\mathrm{P}$ ' is a term, which takes into account the dipole-dipole interaction of the electron moment with the nuclear moment. $\mathrm{A}_{0}$ is the isotropic hyperfine interaction factor obtained from the equation $\mathrm{A}=\left(\mathrm{A}_{\|}+\right.$ $\left.2 \mathrm{~A}_{\perp}\right) / 3 .^{26}$

The molecular orbital coefficient is represented by,

$$
\beta_{2}{ }^{* 2}=(-7 / 6) \Delta \mathrm{g}_{\|}+(5 / 12) \Delta \mathrm{g}_{\perp}+(7 / 6)\left[\left(\mathrm{A}_{\|}-\mathrm{A}_{\perp}\right) / \mathrm{P}\right]
$$

Where $\Delta \mathrm{g}_{\|}=2.0023-\mathrm{g}_{\|}, \Delta \mathrm{g}_{\perp}=2.0023-\mathrm{g}_{\perp} . \beta_{2}{ }^{* 2}$ represents the axial ligand $\pi$-bonding. The evaluated values of $\beta_{2}{ }^{* 2}$ show that the electrons in the in-plane vanadium ligand $\pi$ bonding orbitals are ionic in nature. The calculated values of $\alpha^{2}, \beta_{2}{ }^{* 2}, \mathrm{k}, \mathrm{A}_{\|}, \mathrm{A}_{\perp}, \mathrm{g}_{\|}, \mathrm{g}_{\perp}, \mathrm{A}_{\|}{ }^{1}$ and $\mathrm{A}_{\perp}{ }^{1}$ are depict in Table-1.

The term $C=1-\beta_{2}{ }^{* 2}$ represents the fraction of the delocalization of the unpaired 'd' electrons over ligand orbitals. The average value of $\mathrm{C}=0.024$ indicates the delocalization of the unpaired d-electrons over ligand orbital ${ }^{27}$.

Table - 2: The Values of Direct, Indirect Bandgaps and Urbach Energies of $\mathrm{VO}^{2+}$ Ions doped in PVAZn Polymer

\begin{tabular}{|c|c|c|c|}
\hline \multirow{2}{*}{$\begin{array}{l}\mathrm{VO}^{2+} \\
\mathrm{mol} \%\end{array}$} & \multicolumn{2}{|c|}{ Optical Bandgap Energy (Eopt) } & \multirow{2}{*}{$\begin{array}{c}\text { Urbach Energy } \\
(\mathrm{eV})\end{array}$} \\
\hline & Direct $(\mathrm{eV})$ & Indirect $(\mathrm{eV})$ & \\
\hline 0.2 & 3.12 & 3.67 & 3.15 \\
\hline 0.4 & 2.95 & 3.10 & 2.15 \\
\hline 0.6 & 2.61 & 2.61 & 2.07 \\
\hline 0.8 & 2.53 & 2.53 & 1.25 \\
\hline
\end{tabular}
Films.

\section{FT-IR}

FT-IR spectroscopy used to identify the structural bonds present in the polymer matrix. The FTIR spectra of PVAZn and PVAZn: $\mathrm{VO}^{2+}$ polymer films recorded at room temperature in the wavenumber range 600-2000 $\mathrm{cm}^{-1}$ and shown in Fig.-9(a and b).

From the pure spectra, the bands at $617-738 \mathrm{~cm}^{-1}$ have assigned to $\mathrm{Zn}-\mathrm{O}$ stretching of the polymer complex. The band at $838 \mathrm{~cm}^{-1}$ has assigned to $\mathrm{C}-\mathrm{C}$, which arises from the stretching mode of the host polymer. The bands observed at $1000-1142 \mathrm{~cm}^{-1}$ has assigned to the C-O-C stretching mode formed by the cross-linking of PVA with Zn-O. ${ }^{28,29}$ The bands at $1396 \mathrm{~cm}^{-1}, 1457 \mathrm{~cm}^{-1}, 1520 \mathrm{~cm}^{-1}, 1541 \mathrm{~cm}^{-1}$ has assigned to bending vibrations of the $\mathrm{CH}_{2}$ group. The bands at $1649-1741 \mathrm{~cm}-1$ have attributed to the $\mathrm{C}=\mathrm{O}$ stretching mode. The band at $738 \mathrm{~cm}^{-1}$ splits into 713 and $766 \mathrm{~cm}^{-1}$ due to the addition of vanadium into (PVA+ZnO) matrix. An apparent shifting was observed for 1003, 1079, 1142, 1271, 1396, and $1457 \mathrm{~cm}^{-1}$ bands when vanadium added to the polymer matrix. The shifting of the bands is the clear evidence of vanadium enters into the $(\mathrm{PVA}+\mathrm{ZnO})$ complex. The shifting of these bands in the polymer matrix correlated to the charge transfer reaction between the polymer chain and the dopant.

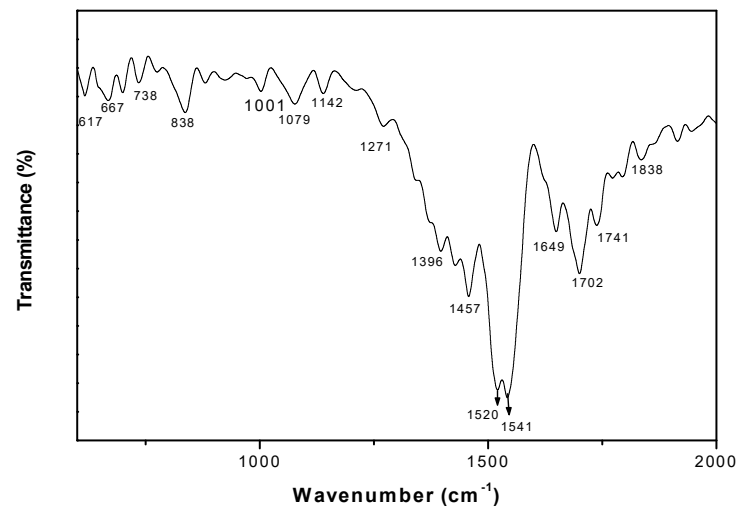

(a)

895 
RASĀYAN J. Chem.

Vol. 13 | No. 2 |887 - 897| April - June | 2020

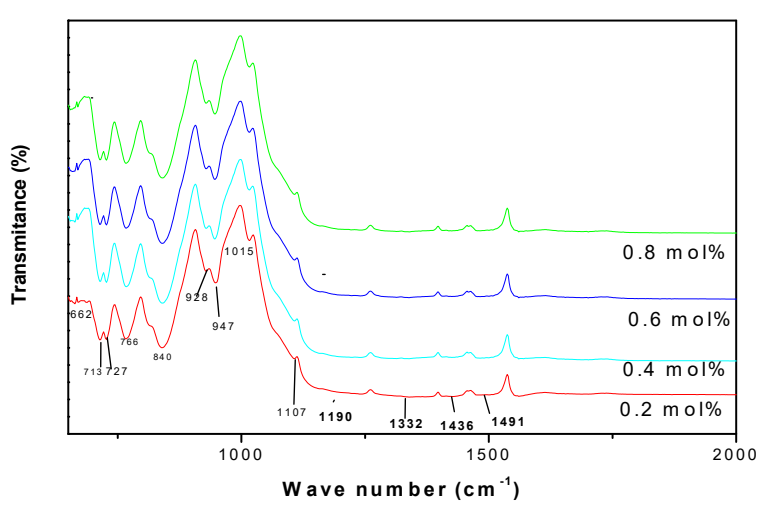

(b)

Fig.-9: FT-IR Spectrum of (a) Pure PVAZn and (b) PVAZn:VO ${ }^{2+}(0.2-0.8 m o l \%)$ Polymer Films recorded at Room Temperature.

The remaining bands are broadened and slowly disappeared after $1142 \mathrm{~cm}^{-1}$ when increasing of vanadium content in PVAZn. All the IR band positions and their corresponding band assignments presented in Table-3.

Table - 3: The IR Band Positions and Their Corresponding Band Assignments of PVAZn and VO ${ }^{2+}: \mathrm{PVAZn}$ Polymer Films.

\begin{tabular}{|c|c|c|c|c|c|}
\hline \multirow{2}{*}{$\begin{array}{c}\text { Pure } \\
\text { (PVAZn) }\end{array}$} & \multicolumn{4}{|c|}{ PVAZn: $\mathrm{VO}^{2+}\left(\mathrm{x} \mathrm{mol}^{2}\right)$} & \multirow{2}{*}{ Band Assignment } \\
\hline & $0.2 \mathrm{~mol} \%$ & $0.4 \mathrm{~mol} \%$ & $0.6 \mathrm{~mol} \%$ & $0.8 \mathrm{~mol} \%$ & \\
\hline \multicolumn{5}{|l|}{617} & \multirow{4}{*}{$\mathrm{Zn}-\mathrm{O}$} \\
\hline 667 & $6 \overline{662}$ & $\overline{659}$ & $\overline{657}$ & $\overline{657}$ & \\
\hline \multirow{2}{*}{738} & 713 & 713 & 714 & 714 & \\
\hline & 766 & 767 & 766 & 767 & \\
\hline 838 & 840 & 840 & 840 & 840 & $\mathrm{C}-\mathrm{C}$ \\
\hline 1003 & 947 & 949 & 949 & 949 & \multirow{3}{*}{$\mathrm{C}-\mathrm{O}-\mathrm{C}$} \\
\hline 1079 & 1015 & 1015 & 1015 & 1015 & \\
\hline 1142 & 1107 & 1107 & 1107 & 1103 & \\
\hline 1271 & 1190 & 1195 & 1195 & 1195 & \multirow{4}{*}{$\mathrm{CH}_{2}$} \\
\hline 1396 & 1337 & 1337 & 1337 & 1337 & \\
\hline 1457 & 1491 & 1491 & 1491 & 1491 & \\
\hline \multicolumn{5}{|l|}{1541} & \\
\hline \multicolumn{5}{|l|}{1649} & \multirow{4}{*}{$\mathrm{C}=\mathrm{O}$} \\
\hline \multicolumn{5}{|l|}{1702} & \\
\hline \multicolumn{5}{|l|}{1741} & \\
\hline 1838 & & & & & \\
\hline
\end{tabular}

\section{CONCLUSION}

- From the EPR spectra of PVAZn: $\mathrm{VO}^{2+}$ polymer films, the $\mathrm{VO}^{2+}$ ions are in tetragonally compressed octahedral sites.

- The spin-Hamiltonian parameters $g$ \& A were calculated. The variation of $\mathrm{N}$ values with the increase of $\mathrm{VO}^{2+}$ ion concentration gives non-monotonic behavior due to the dipole interactions between the vanadyl ions.

- The optical absorption spectra of polymer films exhibit three absorption bands at 421, 692, $832 \mathrm{~nm}$. These bands give characteristics of $\mathrm{VO}^{2+}$ ions in tetragonally distorted octahedral sites.

- From the ultra-violet absorption edges, the optical band gap energies $\left(\mathrm{E}_{\text {opt }}\right)$ calculated. It stimulates to observe that the optical band gap energies for these polymers decrease with increases of vanadium content were found. This change indicates that the polymer films turn into more semiconducting. 
RASĀYAN J. Chem.

Vol. 13 | No. 2 |887 - 897| April - June | 2020

- The FTIR spectra exhibit stretching and bending vibration modes of $\mathrm{Zn}-\mathrm{O}, \mathrm{C}-\mathrm{H}, \mathrm{C}=\mathrm{C}, \mathrm{CH}_{2}$, and CO groups.

\section{REFERENCES}

1. M. I. Abd-Elrahman, Nanoscale and Microscale Thermophysical Engineering, 17, 194(2013), DOI: $10.1080 / 15567265.2013 .776152$

2. Nabil Shash, Ionics, 19, 1825(2013), DOI:10.1007/s11581-013-0923-0

3. Ch. Liga Raju, K.V.Narasimhulu, N.O.Gopal, J.L. Rao, B.C.V.Reddy, Journal of Molecular Structure, 754, 100(2005), DOI: 10.1016/j.molstruc.2005.07.006

4. A.S. Kutsenk, S.M. Maloletor, S.Y.A. Kuchmiletal, Ukirainian Journal of Physics, 49(12A), A34(2004).

5. A. A. Ostroushko, M.Yu. Sennikov, Russian Journal of Inorganic Chemistry 54, 115(2009), DOI: $10.1134 / \mathrm{S} 0036023609010185$

6. Manoj Kumar Gupta, Ju-Hyuck Lee, Keun Young Lee, Sang-Woo Kim, American Chemical Society Nano, 7(10), 8932(2013), DOI:10.1021/nn403428m

7. A. Abragam, B. Bleaney, Electron Paramagnetic Resonance of Transition Ions, Clarendon Press, Oxford, 175(1970).

8. S. Khasa, V. P. Seth, Ashish Agarwal, R. Murali Krishna, S. K. Guptha, Prem Chand, Journal of Material Chemistry and Physics, 72(3), 366(2001), DOI: 10.1016/S0254-0584(01)00317-0

9. O. Cozar, I. Ardelean, V. Simon, L. David, V. Mih, N. Vedean, Applied Magnetic Resonance, 16, 529(1999), DOI: 10.1007/BF03161948

10. O. Cozar, I. Ardelean, V. Simon, G. Ilonca, C. Cracium, C. Cefan, Journal of alloys and Compounds, 326, 124(2001), DOI: 10.1016/S0925-8388(01)01247-6

11. I. Omkaram, R. P. Sreekanth Chakradhar, J. Lakshmana Rao, Physica B, 388, 318(2007), DOI: 10.1016/j.physb.2006.06.134

12. R. Muncaster, S. Parke, Journal of Non-Crystalline Solids, 24, 399(1977), DOI:10.1016/00223093(77)90107-7

13. B. Bleaney, K.W.H. Stevens, Reports on Progress in Physics, 16, 108(1953), DOI:10.1088/ 0034$4885 / 16 / 1 / 304 / p d f$

14. B. Yasoda, R. P. Sreekanth Chakradhar, J. L. Rao, N. O. Gopal, Material Chemistry Physics, 106, 33(2007), DOI: 10.1063/1.5130252

15. N. Kerkouri, M. Haddad, M. Et. Tabirou, A. Chahine, L. Laanab, Physica B, 406, 3142(2011), DOI: 10.1016/j.physb.2011.04.057

16. J. A. Weil, J. R. Bolton, J. E. Wertz, Electron paramagnetic Resonance-Elementary Theory and Practical Applications Wiley, New York, 498(1994), DOI:10.1002/recl.19951140115

17. Ch. Liga Raju, J. L. Rao, N. O. Gopal, K.V. Narasimhulu, B. C. V. Reddy, Material Chemistry and Physics, 101, 423(2007), DOI:10.1016/j.matchemphys.2006.08.001

18. M. A. Hassan, C. A. Hogarth, Journal of Material Science, 23, 2500(1988), DOI:10.1007/ BF01111908

19. N.W. Aschcroft, N. N. Mermin, Solid State Physics, Harcourt, Fort worth, TX, 656(2001).

20. R. Kripal, S. Shukla, Spectroscopy Letters, 44, 235(2011), DOI:10.1080/00387010.2010. 506905

21. Ballhausen, 'Introduction to Ligand Field Theory', Mc Graw Hill, New York (1962).

22. D. Kivelson. S.Lee, Journal of Chemical Physics, 41,1896(1964), DOI:10.1063/1.1726180

23. C. M. Brodbeck, L. E. Iton, Journal of Chemical Physics, 83, 4285(1958), DOI:10.1063/1.449041

24. B. Sumalatha, I. Omkaram, T. Rajavardhanarao, Ch. Linga Raju, Non- Crystalline Solids, 357, 3143(2011), DOI:10.1016/j.jnoncrysol.2011.05.005

25. T. Blasco, L. Fernandez, A. Martinez-Arias, M. Sanchez- Sanchez, P. Concepcion, J. M. L. Nieto, Mesopor, Microporous Mesoporous Materials, 39, 219(2000), DOI:10.1023/A:10166059 16860

26. J. A. McMillan, T. Halpern, Journal of Chemical Physics, 55, 33(1971).

27. K. V. Narayana, B. David Raju, S. Khaja Martin, V. Venkat Rao, P. Kantha Rao, R. Subrahmanian, A. Martin, Catalysts Catalysis Communications, 5, 457(2004), DOI:10.1016/j.catcom.2004.05.012

28. Ibrahim Uslu, Burcu Baser, Ahmet Yayli, Mehmet Levent Aksu, e-Polymers, 145,(2007), DOI: 10.1515/epoly.2007.7.1.1699

29. E. M. Abdelrazek, A. M. Abdelghany, A. H. Oraby, G. M. Asnag, IJET- International Journals of Engineering \& Technology, 12(4), 4343(2012).

[RJC-5582/2019] 